\title{
PLoS stays afloat with bulk publishing
}

Public Library of Science (PLoS), the poster child of the open-access publishing movement, is following an haute couture model of science publishing - relying on bulk, cheap publishing of lower quality papers to subsidize its handful of high-quality flagship journals.

Since its launch in 2002, PLoS has been kept afloat financially by some US $\$ 17.3$ million in philanthropic grants. An analysis by Nature of the company's accounts shows that PLoS still relies heavily on charity funding, and falls far short of its stated goal of quickly breaking even through its business model of charging authors a fee to publish in its journals. In the past financial year, ending 30 September 2007, its \$6.68-million spending outstripped its revenue of $\$ 2.86$ million, according to the publicly available accounts.

But its financial future is looking brighter thanks to a cash cow in the form of PLoS One, an online database that PLoS launched in December 2006. PLoS One uses a system of 'light' peer-review to publish any article considered methodologically sound. In its first full year of operation in 2007, PLoS One published

\section{"PLoS trumpeted} its business model as being better than everyone else's." very clear that the reality is very far from PLoS's original plan," says John Ewing, executive director of the American Mathematical Society. In particular, PLoS's initial projections overestimated by an order of magnitude the number of articles that both its top- and second-tier journals would attract, tax-record data obtained by Nature reveal. PLoS also grossly underestimated the cost of producing its top-tier journals.

"If the original model was to be self-sustaining through author fees, it seems that PLoS is not even half-way there," says Bernard Rous, deputy director of publications of the Association for Computing Machinery, the world's largest educational and scientific computing society. Nevertheless, Rous endorses PLoS's strategy of tapping multiple revenue sources and cross-subsidizing to allow open access to all its titles.

Faced with an increasingly dire financial situation, PLoS hiked all its author fees in 1,230 articles, which would have generated an estimated \$1.54 million in author fees, around half of PLoS's total income that year. By comparison, the 321 articles published in PLoS Biology in 2007 brought in less than half this amount.

From the outset, the company consciously decided to subsidize its top-tier titles by publishing second-tier community journals with high acceptance rates that would be cheaper to produce. In addition to its premium titles - PLoS Biology and PLoS Medicine, which have low acceptance rates and high overheads, and charge author fees of $\$ 2,750$ - it has launched four lower-cost journals that are run by volunteer academic editorial teams rather than in-house staff. At \$2,100, the fees to authors for publishing in these journals - PLoS Computational Biology, PLoS Genetics, PLoS Pathogens and PLoS Neglected Tropical Diseases — are almost as much as those for its top journals.

But this combination has generated much less income than PLoS envisaged. "It's

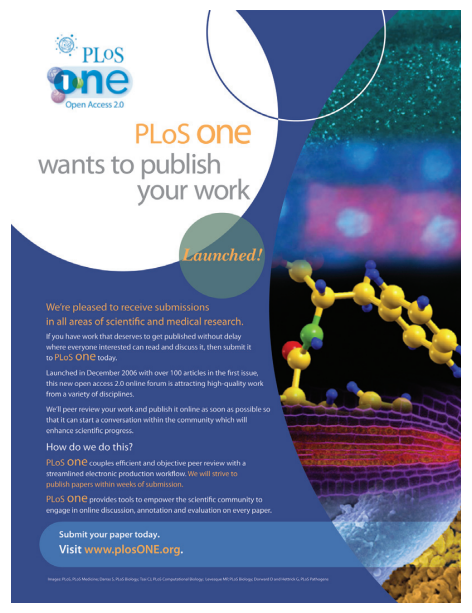
compared with the new cash flowing from the flood of articles appearing in PLoS One. Since it launched, PLoS One has published 2,526 articles - more than PLoS Biology has published in its five years of existence, and that growth shows no signs of abating. PLoS One has published 1,158 papers since the beginning of this year, which is almost as many as it published during the whole of 2007. Another factor is that it costs authors only $\$ 1,250$ to publish in PLoS One.

"It's fair to say that the community-run journals, including PLoS One, are contributing very well to our overall financial picture, says Peter Jerram, chief executive of PLoS, adding: "PLoS is on track to be self-sustaining within two years. In the interim some philanthropic support will be needed.

"It's tremendous to see how the progress that PLoS has made over the years has been mirrored by the great strides taken towards openaccess to research more broadly," Jerram says.

Papers submitted to PLoS One are sent to a member of its editorial board of around 500 researchers,

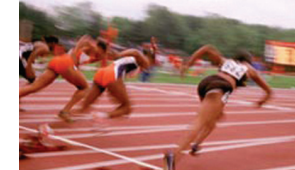

LANE DISCIPLINE?

Olympic sprints hits more controversy

www.nature.com/news

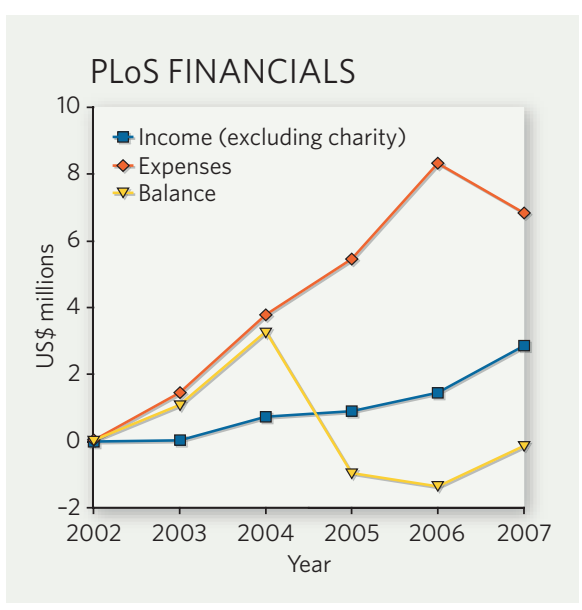

who may opt to review it themselves or send it to their choice of referee. But referees only check for serious methodological flaws, and not the importance of the result. The board members who Nature spoke to were generally positive about the overall quality of the papers they had received to review and the referees reports they solicited.

"There's so much in PLoS One that it is difficult to judge the overall quality and, simply because of this volume, it's going to be considered a dumping ground, justified or not, says John Hawley, executive director of the freeaccess Journal of Clinical Investigation. "But nonetheless, it introduces a sub-standard journal to their mix."

Hawley says it's unsurprising that the PLoS business model has come under scrutiny. "PLoS trumpeted its business model as being better than everyone else's, as being 'the one." The tack taken by BioMed Central, a Londonbased open-access company, of publishing mostly lower-impact journals in a wide variety of disciplines "is probably closer to what works in open access", he says.

BioMed Central has an estimated annual revenue of around $£ 10$ million ( $\$ 20$ million). It is already "pleasantly profitable", according to a science-publishing consultant who asked to remain anonymous. "BioMed Central knows well that much of the journal middle order is more profitable than the great brands because of the lower editorial costs and the cheaper marketing costs for bundles of journals. I suspect that PLoS One is a result of learning the same lesson," he adds.

BioMed Central is now up for sale, which will be a "fascinating first market test of what people will pay for an open-access company".

Declan Butler 